\title{
ENFERMAGEM OBSTÉTRICA: ASSISTÊNCIA AO PARTO NO BRASIL REFLEXOS DA COLONIALIDADE DO PODER E DO SABER ${ }^{1}$
}

\author{
Tainá Santana de Deus Oliveira* \\ Mary Lúcia Souto Galvão** \\ Ticiana Oswald Ramos ${ }^{* * *}$
}

\section{RESUMO}

Trata-se de uma revisão integrativa bibliográfica, de caráter exploratório e qualitativo, que objetivou analisar a influência da colonialidade do poder, e do saber, nas práticas assistenciais das enfermeiras obstetras no parto institucional, apresentando as conflitualidades existentes entre os profissionais que atuam no campo da assistência ao parto, e caracterizando o modelo assistencial hegemônico no Brasil. O levantamento bibliográfico foi feito na Biblioteca Virtual de Saúde. Os documentos foram analisados através do método análise temática de conteúdos. Emergiram três temáticas: Reflexões acerca da Colonialidade do Poder e do Saber na Saúde; Panorama da assistência obstétrica: o modelo hegemônico; O potencial da Enfermeira Obstetra. Constatou-se que o há conflitualidades no campo da atuação da enfermeira obstetra, decorrentes de processos históricos associados à Colonialidade do Poder e Saber, desencadeados a partir da institucionalização do parto.

Palavras-chaves: Enfermagem Obstétrica; Modelos de Assistência à Saúde; Colonialidade do poder/saber.

\section{INTRODUÇÃO}

A situação da enfermagem obstétrica no Brasil está associada ao processo de construção dessa profissão, o que implica em mudanças históricas e culturais em torno da assistência ao parto. Diante desse contexto, surge o interesse em pesquisar sobre o lugar da Enfermeira Obstetra (EO) na assistência ao parto institucional no Brasil, tomando como referência a influência da colonialidade do poder, e do saber, sob o modelo assistencial obstétrico preponderante. Esta revisão integrativa bibliográfica tem como objetivos analisar a influência da colonialidade do poder, e do saber nas práticas assistenciais das EO no

\footnotetext{
* Universidade do Estado da Bahia - UNEB. Rua Silveira Martins, 2555, Cabula. CEP: 41.150-000 - Salvador - Bahia, Brasil. taina.sdo@gmail.com https://orcid.org/0000-0002-9418-4378

** Universidade do Estado da Bahia - UNEB. Rua Silveira Martins, 2555, Cabula. CEP: 41.150-000 - Salvador - Bahia, Brasil.mgalvao@uneb.br https://orcid.org/0000-0003-2744-1773

*** Universidade Federal do Recôncavo da Bahia, Centro de Ciências da Saúde, Campus Santo Antônio de Jesus. Avenida Carlos Amaral, R. do Cajueiro, 1015, Santo Antônio de Jesus - Bahia, Brasil. CEP 44574-490. ticianaor@gmail.com https://orcid.org/0000-0001-8765-2340

${ }_{1}^{1}$ Trabalho de conclusão de curso apresentado ao Colegiado de Enfermagem da Universidade do Estado da Bahia como requisito final para obtenção do grau de Bacharel em Enfermagem.
} 
parto institucional no Brasil, apresentando as conflitualidades encontradas por essas profissionais no processo de trabalho no campo da assistência ao parto, caracterizando o modelo assistencial implantado no Brasil a partir da institucionalização do parto.

Historicamente, a responsabilidade pelo cuidado da mulher no processo parturitivo era exclusivamente feminina, realizado por parteiras que eram conhecidas e reconhecidas na comunidade onde atuavam. Com o advento da ciência moderna a assistência ao parto foi institucionalizada através da hospitalização da parturiente (SANFELICE et. al, 2014).

Em meados do século XVII, com o surgimento da obstetrícia, ocorreu a entrada dos homens no atendimento às gestantes. A entrada da categoria médica na assistência ao parto transferiu este processo para o ambiente hospitalar, desencadeando uma mudança estrutural no modelo assistencial. No Brasil, essa assistência expandiu-se mundialmente como padrão, e perdurou até a década de oitenta como ideário e como política pública (CAUS et. al, 2012).

No século XVIII, com o advento do capitalismo, ocorreu o desenvolvimento vertiginoso da medicina moderna associado ao maior interesse médico pela saúde reprodutiva, papel relevante no controle das populações, acarretando a incorporação da obstetrícia à medicina. No Brasil esse processo começou a repercutir no início do século XIX, quando são fundadas pela Família Real, instituições responsáveis pelo licenciamento das parteiras, incluindo no cenário do parto os médicos, parteiras examinadas, parteiras diplomadas, e posteriormente as obstetrizes e enfermeiras obstetras (MENEZES et. al, 2012).

Neste novo cenário consolidou-se a exigência da formação técnica das parteiras, que deveriam ter suas habilidades validadas pela escola de medicina da época, para tanto, eram submetidas a um exame teórico e prático para obter a comprovação de sua experiência através de carta expedida pelo físico mor da região onde moravam. Embora reconhecendo que as parteiras eram legitimadas a partir do seu saber empírico, as mudanças promovidas pela institucionalização exigiam que seu conhecimento fosse aprovado e validado pelo saber médico (MOTT, 2001).

Nessa perspectiva, as mudanças estruturais da sociedade industrial e do capitalismo em seus processos econômicos, políticos e sociais, agregaram novas formas de cuidar à medicina moderna, lhe atribuindo significados próprios, com grande aparato tecnológico, gerando mudanças importantes dos papéis sociais simbolizados na figura dos médicos que passaram a representar a posição central no processo da assistência ao parto, 
enquanto as mulheres foram realocadas para um plano secundário, destituindo-a da autonomia sobre seu corpo (DAVIS-FLOYD, 1994).

À medida que os médicos acumulavam o conhecimento, o sistematizando e institucionalizando-o, o elitizaram e dominaram, para convencer a sociedade que eles eram os únicos com condições de resolver seus problemas de saúde. Assim, foi necessário despersonalizar as parteiras, retirar as mulheres dos seus lares, separá-las de suas famílias e de suas relações sociais para se obter o controle total sob o parto (OSAVA, 2009).

O processo de medicalização no Brasil, portanto, foi desencadeado a partir do projeto modernizador republicano, que depositou em uma versão colonial, patriarcal e eugenista de ciência, a proposta de um novo modelo de assistência ao parto. Essa concepção fundamentou uma convergência identitária entre saúde, educação e nação, unindo a intelectualidade urbana para elaboração de uma ampla proposta reformadora ancorada no projeto higienista como eixo central (RAMOS, 2013).

Nesse contexto, a institucionalização do parto pode ser considerada um dispositivo da colonialidade do poder, pois gradativamente desqualificou todos os saberes que não estavam alinhados ao pensamento hegemônico intrinsecamente ligados aos processos que relacionam a medicalização da vida e a validação do modelo biomédico de assistência em saúde, resultando no modelo hegemônico que articula o capitalismo global ao biopoder.

Em múltiplos cenários da assistência ao parto, se constata indubitavelmente a hegemonia do modelo tecnocrático de assistência, desenvolvido pela antropóloga Robbie Davis- Floyd (2003), que propõe a coexistência de três modelos: tecnocrático, humanista e holista.

A Organização Mundial de Saúde (OMS) recomenda a participação da Enfermeira Obstetra na assistência ao parto tomando como referência o cuidado em detrimento das excessivas intervenções presentes no modelo tecnocrata. Essa profissional contribui para a redução dos altos índices de mortalidade materna, que representam indicadores de avaliação das condições de vida e saúde da população feminina, expressando a crítica situação da assistência obstétrica em nosso país (RAMOS et. al, 2018).

Embora órgãos oficiais como o Ministério da Saúde e Agência Nacional de Saúde Suplementar, e entidades internacionais, como a OMS, reconheçam a EO como a profissional indicada para prestar assistência à mulher no ciclo gravídico-puerperal de risco habitual, na prática essas diretrizes não são seguidas pelas instituições de saúde. A gestão das instituições preserva a hierarquia médica, dando respaldo aos médicos para trabalharem 
sem adesão a protocolos clínicos definidos no serviço, privilegiando condutas que nem sempre estão de acordo com a natureza do processo de parto. EO e médico obstetra, em geral, não compartilham do mesmo paradigma de atenção às mulheres no âmbito da assistência ao parto, sendo as atividades e intervenções médicas consideradas mais valorizadas que os cuidados de enfermagem à mulher desencadeando conflitualidades, que dificulta o trabalho colaborativo (RAMOS et. al, 2018).

A atuação da enfermeira obstetra também está prevista na Rede Cegonha (2011), política que preconiza a mudança do modelo de atenção ao parto, visando qualificar os indicadores maternos neonatais. Dessa forma, elencamos a colonialidade do poder, e do saber, como dispositivo de influência no processo de trabalho da enfermeira obstetra, propondo reflexões que ampliem a compreensão acerca do modelo hegemônico de assistência.

\section{COLONIALIDADE DO PODER, E DO SABER}

Originalmente o conceito de Colonialidade do Poder foi desenvolvido por Aníbal Quijano, em 1989, quando apresentou uma teoria sobre as relações de colonialidade nas esferas econômica e política, discordando da instituição do colonialismo. Esse conceito possui uma capacidade explicativa que atualiza e contemporiza os processos, que supostamente teriam sido apagados, assimilados ou superados pela modernidade. Para ele, a colonialidade do saber constitui a repressão de outras formas de produção de conhecimento não-europeias, negando o legado intelectual e histórico de povos indígenas e africanos (QUIJANO, 2005).

Nessa perspectiva, a conquista ocidental submeteu a América Latina, a África e a Ásia, a uma estrutura de dominação, fragilizando o imaginário dos povos colonizados para subalternizá-los, reprimindo seus modos de produção, conhecimentos e saberes (QUIJANO, 2005).

Nos seus estudos, Boaventura de Sousa Santos explica através do "Pensamento Abissal" a divisão do mundo em dois lados "deste lado da linha" e o "do outro lado da linha", onde o "outro lado", o colonizado, passou a ser inexistente, porque as sociedades colonizadas tiveram seu desenvolvimento baseado na dicotomia entre apropriação, incorporação, cooptação, assimilação/violência, destruição física, material, cultural e humana. O autor afirma que o conhecimento dito moderno representa manifestação legítima do pensamento abissal, no qual a ciência monopolizou o conhecimento universal entre o verdadeiro e o falso em detrimento de conhecimentos alternativos. 
Assim, Boaventura propõe as bases do pensamento pós-abissal, que aborda a Epistemologia do Sul, confrontando a monocultura da ciência moderna e defendendo a "ecologia de saberes", que reconhece e valoriza a pluralidade dos conhecimentos heterogêneos em constantes interações sustentáveis e dinâmicas, entre si, sem comprometer sua autonomia na medida em que se fundamenta no reconhecimento da pluralidade (SANTOS, 2007).

A civilização moderna ocidental, que se constituiu enquanto representação dominante dos países do norte europeu, autodescreve-se como mais desenvolvida e superior, sustentando inconscientemente uma posição eurocêntrica. Esta dominação produz vítimas, de muitas e variadas maneiras, violência que é interpretada como um ato inevitável. Essa lógica coloca a modernidade como processo emancipatório culpabilizando o outro, bem como todos os discursos, que a constituem (LANDER, 2005).

As repercussões da ciência moderna sobre a vida, resultam na destruição do potencial cultural das pessoas para lidarem de forma autônoma com a enfermidade, com a dor e com a morte, causando a regressão estrutural do nível de saúde. A destruição deste potencial está vinculada à invisibilidade, apropriação e perseguição. A invisibilidade foi introduzida para negar a existência dos saberes tradicionais, através de adjetivos que desqualificam esse bem cultural, tais como, crendice, magia e primitivismo (SANTOS, 2007).

A medicalização da vida e da sociedade constitui um processo em franca expansão internacional tendo como marco inicial o surgimento da biomedicina entre o final do século XVIII e o início do XIX, simultâneo ao fenômeno da industrialização e reorganização dos modos de vida nas cidades.

Os fundamentos críticos sobre o processo de medicalização com a noção do imperialismo médico, termo usado para se referir ao processo de supervisão médica de todos os aspectos ordinários da vida, enquanto produto da industrialização, responsável pela profissionalização e a burocratização da instituição médica foram elaborados por Illich que visualiza a medicalização como processo de grave ameaça para a saúde. Ele criou a noção de iatrogênese - iatros (médico) e gênesis (origem) - para denunciar a nova epidemia de intercorrências, danos e intervenções inapropriadas provocadas pela medicina. Ele afirma que embora o sistema médico tenha sido criado para proteger a saúde, produz paradoxalmente mais doenças (ILLICH, 1975).

Por meio da discussão deste tópico, podemos demonstrar alguns elementos sobre os desdobramentos da colonialidade em todas as esferas de vida. Os modos de vivenciar, 
diagnosticar, tratar e cuidar da saúde, dos sofrimentos e adoecimentos também estão incluídos nos processos da colonialidade do saber e do poder, bem como a ecologia de saberes, como estratégia de resistência e contraposição à colonialidade.

\title{
INSTITUCIONALIZAÇÃO DO PARTO
}

A partir de meados do século XVII, quando a medicina começou a se desenvolver tecnicamente, a assistência ao parto foi transferida do âmbito domiciliar para o hospital sob o cuidado dos médicos, ainda pouco familiarizados com a fisiologia do parto e nascimento. Até então esses cuidados eram oferecidos por parteiras tradicionais que acumulavam o saber empírico, transmitido através da oralidade reforçando os laços de solidariedade feminina como descreve Ruth Hitomi Osava. Os cuidados das parteiras tradicionais ofereciam apoio, segurança e conforto à parturiente, representando o modo mais humano de assistência (GARCIA et. al, 2010; OSAVA, 2009).

Para Osava (2009):

\begin{abstract}
Os historiadores tendem a assumir que a rede de solidariedade das mulheres no parto desapareceu no momento em que homens começaram a atender partos. Leavitt discorda: não foi a entrada de homens que quebrou as redes de solidariedade femininas - as mulheres continuaram a ajudar umas às outras e a controlar os eventos do nascimento enquanto o parto era assistido fora do hospital. É no ingresso ao hospital que se esgarçaram essas redes (OSAVA, 2009. p. 2).
\end{abstract}

Ao enfraquecer os laços de solidariedade no processo do parto, transformando o rito natural em um procedimento onde impera a padronização e tecnificação dos cuidados, o parto assumiu um modelo tecnocrático-hospitalar, representado pela transmissão da cultura globalizada, guiada pela ciência, tecnologia, pelo lucro e pelo controle institucional dos corpos femininos. Cada vez que uma mulher é submetida a um parto guiado por máquinas, hormônios sintéticos e procedimentos invasivos, ela é afastada do protagonismo desse fenômeno, fortalecendo o poder patriarcal estatal, que é intermediado pela ação técnico-profissional (CARNEIRO, 2015).

Os estudos a respeito da qualidade da assistência obstétrica nas maternidades públicas brasileiras, denunciam o alto grau de violência ao qual as mulheres pobres e negras ainda estão submetidas na atualidade. Os resultados identificam preconceitos, estereótipos de gênero e etnia que estão enraizados no imaginário dos profissionais médicos, outorgando o direito de destratar e desrespeitar as mulheres em situação de vulnerabilidade. A violência obstétrica às mulheres foi construída a partir da conjunção de valores simbólicos e dos significados negativos, expressos na estruturação e nas práticas do 
cuidado dispensado. Assim, o corpo feminino vem sendo submetido ao processo de medicalização desde institucionalização médico-hospitalar, viabilizando o exercício da clínica, da cirurgia, da obstetrícia, bem como o desenvolvimento de pesquisas em favor da maternidade (MCCALLUM; REIS, 2006; AQUINO, 2014; SANTOS; MENEZES, 2010; LEAL, 2014).

A medicina enquanto categoria, instituiu estratégias de controle sobre o corpo individual e coletivo, para exercer o poder sobre a vida das populações.

\section{BIOPODER E MODELOS DE ASSISTÊNCIA AO PARTO}

O desenvolvimento da ciência médica como poder social foi estudado por Foucault para descrever a sociedade na qual a população é controlada pela medicina através dos dispositivos disciplinares. A partir do século XIX foi estabelecido uma associação entre o poder sobre o corpo do indivíduo e o poder sobre o corpo coletivo, gerando um poder cuja tecnologia une dois elementos indispensáveis para o controle da vida: a fisiologia dos corpos e seus ciclos vitais. As instituições reguladoras e a biopolítica formam uma aliança útil no exercício da gestão da vida, e encontram no fenômeno da medicalização, um lugar de ação, visto que a medicalização se caracteriza pela intervenção médica sobre o plano da vida dos sujeitos, exercendo um controle sobre a população e o indivíduo, caracterizando assim o biopoder (ZORZANELLI; CRUZ, 2018).

A especialização técnica constituiu uma estratégia importante para legitimação do progresso científico e para desumanização da relação entre medicina e demandas sociais. A biotecnologia médica responde inadequadamente a demanda social por saúde e cuidados, deslocando-se do segmento social e revelando dificuldades para escutar, traduzir e compreender o sentido social da dor e do sofrimento. O estudo de Martins (2003) aponta uma organização disciplinar da ciência médica submetida aos interesses do mercado, colocando em plano secundário os compromissos sociais do seu campo de saber. O capitalismo médico impõe um modelo de saber técnico que obedece a divisão disciplinar do campo científico, uma visão utilitarista e econômica do corpo humano num processo de ruptura das relações entre médico e clientes. Assim, supervaloriza a tecnologia e contribui para produção de medicamentos, equipamentos e serviços médicos hospitalares, vulnerabilizando a relação entre especialização e ciência. A medicina passou a atender ao mercado de acumulação de lucros desencadeando o descompasso entre a lógica do investimento em tecnologia e a lógica das doenças sociais (MARTINS, 2003). 
A crescente medicalização da vida cotidiana encontrou eco na formação das sociedades disciplinadoras adotando a instituição médica, que transformou o hospital em espaço legítimo de biopoder, constituindo um instrumento de consolidação do capitalismo na medida em que, contribuiu para a normatização da vida privada construindo o conceito de corpo como máquina para atender as demandas do período industrial. Essa concepção utilizou o corpo como estratégia biopolítica para o controle populacional (FOUCAULT, 2018).

A legitimação da medicina científica, com sua intervenção na saúde através de estados nacionais, tecnocracia e hospitalização fortalecida pelo biopoder, estão atrelados à medicalização. Os hospitais foram transformados em espaços de produção de normalidade, onde os nascimentos e por consequência os partos se tornaram objeto de interesse do estado e tema de atenção da biopolítica (RAMOS, 2013).

Diante deste panorama de medicalização excessiva, constata-se que o parto também foi vinculado ao desenvolvimento da modernidade pelas várias características do biopoder e da institucionalização que transformou este processo em um evento médico.

O modelo biomédico foi introduzido no âmbito da assistência ao parto no final do século XVIII ocasionando um impacto significativo aos sentidos subjetivos da vinculação mãe-filho, uma vez que todo o processo de intervenção presente na assistência institucional médica, inibe ou proíbe o contato imediato entre os sujeitos principais desse ritual (DINIZ, 2005).

Este modelo assistencial foi implantado no Brasil, no final do século XIX, e é marcado pela verticalidade e centralidade da formulação e implementação das políticas de saúde, impactando na restrição da participação da comunidade, e gerando, entre outros aspectos, a incapacidade de atender às necessidades específicas da população assistida, fortalecendo a hegemonia das práticas assistenciais curativas, que estão direcionadas para o indivíduo, na perspectiva da doença (PAIM, 2001).

O modelo biomédico de assistência ao parto foi legitimado através da cultura do medo da dor, sendo esse dispositivo o responsável por alavancar a epidemia das cesarianas, engendrando silêncio, violências e rechaçando a diversidade das experiências sociais e culturais inerentes das hierarquias e assimetrias relacionais. Este modelo se fundamentou no pressuposto de que somente o médico sabe o que é importante para a saúde do paciente e só ele é capacitado para lidar com a situação, sobrepondo o fato de que conhecimento acerca da saúde deveria ser racional, científico, baseado na observação objetiva de dados 
clínicos, pautado na análise de testes de laboratório e na medição de parâmetros físicos (CAPRA, 2001; MELO, 2013).

O discurso médico inserido na sociedade ocidental está marcado pela tecnomedicina que objetifica o sujeito e mecaniza o corpo, supervalorizando a especialidade que detém o conhecimento. No processo do cuidado a medicina se apropria da intervenção para normatizar e universalizar o conhecimento, desvalorizando outras formas de saberes no campo do cuidado. Consequentemente é criado um cenário de altas taxas de intervenções no processo do parto, com uma série de morbidades associadas, alta razão de mortalidade e insatisfação das mulheres, como demonstram os resultados do Inquérito Nascer no Brasil (DAVIS-FLOYD, 1997; LEAL, 2014).

Nesta perspectiva, constata-se que ainda predomina nas maternidades de todo o país o modelo biomédico, onde o corpo da mulher é tratado como uma máquina, considerado inferior ao corpo do homem, que valida a utilização excessiva da tecnologia, baseada na falsa ideia de segurança. As características e princípios desses modelos de forma sistematizada podem ser vistos na figura abaixo, reproduzida do estudo de Ramos (2013).

Quadro 1- Modelos de Assistência ao parto segundo Robbie Davis-Floyd

\begin{tabular}{|c|c|c|c|}
\hline Modelos médicos & Características & $\begin{array}{l}\text { Princípio } \\
\text { básico }\end{array}$ & $\begin{array}{c}\text { Tipo de } \\
\text { pensamento }\end{array}$ \\
\hline Tecnocrático & 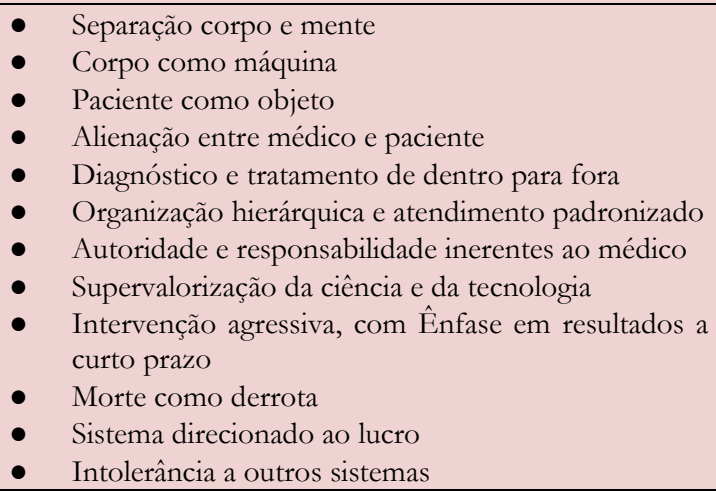 & Separação & $\begin{array}{l}\text { Unimodal, cerebral, } \\
\text { esquerdo, linear }\end{array}$ \\
\hline Humanista & 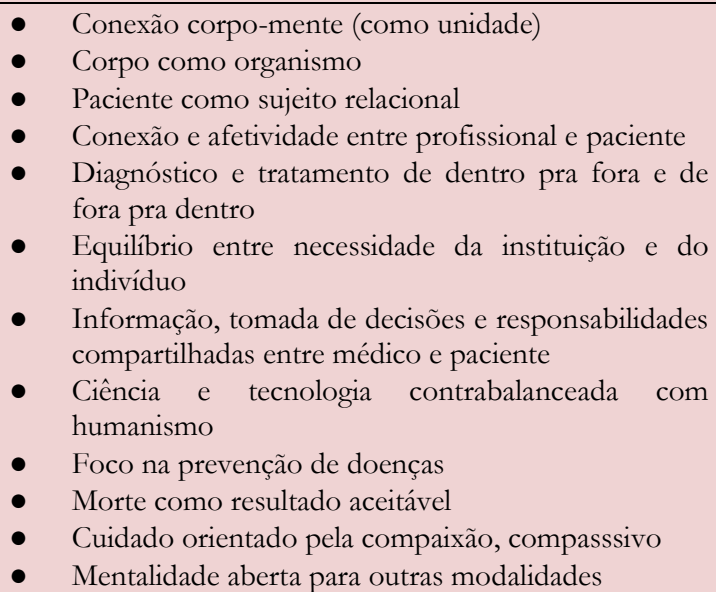 & $\begin{array}{l}\text { Equilíbrio } \mathrm{e} \\
\text { conexão }\end{array}$ & Bimodal \\
\hline Holístico & $\begin{array}{l}\text { - Corpo, mente e espírito como unidade } \\
\text { - Corpo como sistema energético ligado à outros } \\
\text { sistemas } \\
\text { - Cura "holística" (a pessoa inteira na sua vida pos }\end{array}$ & $\begin{array}{ll}\text { Conexão } & \mathrm{e} \\
\text { integração } & \end{array}$ & $\begin{array}{l}\text { Multimodal, cerebral- } \\
\text { direito, fluido }\end{array}$ \\
\hline
\end{tabular}




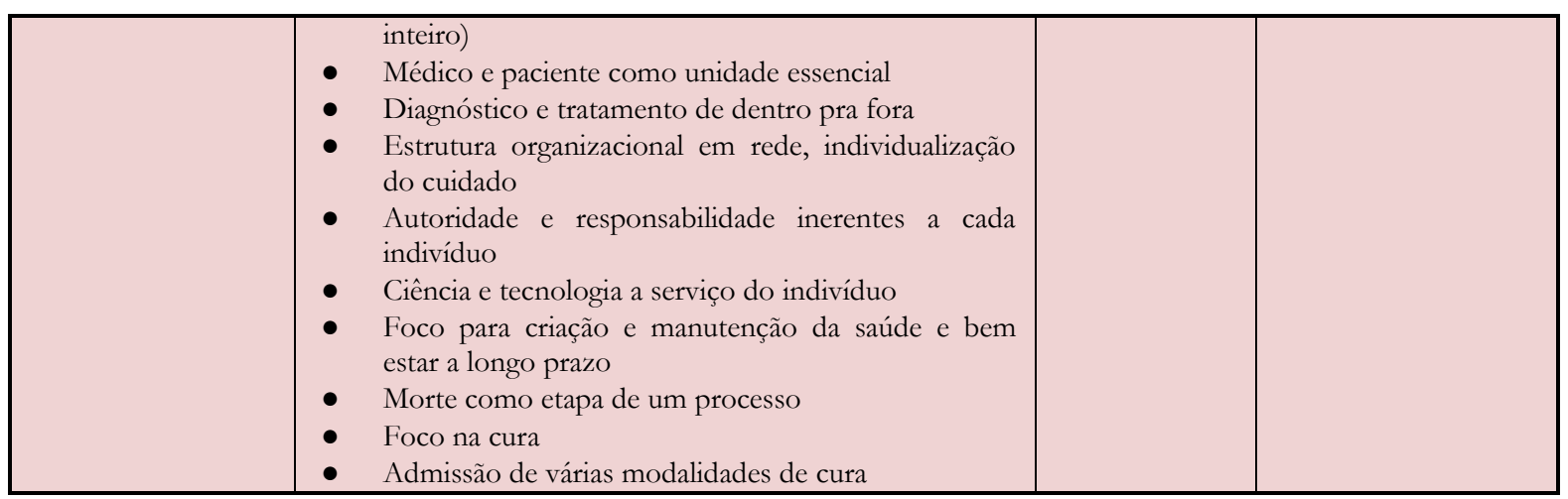

Fonte: $\operatorname{Ramos}(2013$, p. 56)

No Brasil, 98.4\% dos partos ocorrem em hospitais e destes 88,7\% são assistidos por médicos. Diante desses dados, pode-se afirmar que o modelo de assistência ao parto hegemônico no país é o modelo tecnocrático, entretanto também existem muitas iniciativas voltadas para a humanização de partos e nascimentos que buscam fortalecer o modelo humanista, bem como em menor medida pessoas implicadas em um modelo holístico, seja a partir das culturas tradicionais, como é o caso das Parteiras, seja em novas concepções de parteria urbana que buscam se afirmar aproximadamente desde a última década (LEAL, 2014).

\section{A HUMANIZAÇÃO DO PARTO E O LUGAR DA ENFERMEIRA OBSTETRA}

Como discutido anteriormente a colonialidade do poder e do saber, foi utilizada como dispositivo da ciência moderna para assumir o controle das populações, utilizando o corpo da mulher através da institucionalização do parto. Embora esse processo tenha contribuído para a qualidade da assistência obstétrica através dos recursos tecnológicos, desencadeou uma cascata de intervenções resultando em iatrogenias que repercutiram severamente sobre a saúde da mulher.

A institucionalização do processo parturitivo, bem como o modelo biomédico, intervencionista, tecnocrático (como aponta Davis-Floyd), transformou o processo fisiológico de parir, em um processo potencialmente perigoso, com desfechos incertos. A Pesquisa Nascer no Brasil $^{2}$ descreve o panorama nacional da assistência ao parto,

\footnotetext{
${ }^{2}$ A Pesquisa Nascer no Brasil foi coordenada pela FIOCRUZ e contemplou 266 maternidades que realizavam 500 ou mais partos por ano, representando 83\% de parto no País em 191 municípios brasileiros. Incluiu 23.940 mulheres entrevistadas, de Fevereiro de 2011 a Outubro 2012 (LEAL, 2014).
} 
denunciando evidências contundentes em um quadro de desigualdades socioeconômicas, raciais e regionais na atenção obstétrica. $\mathrm{O}$ modelo tecnocrático de atenção ao Parto e nascimento, oferecido pelo SUS e pela rede suplementar ou privada, potencializa as desigualdades desencadeando problemas, tais como: a desarticulação entre o pré-natal e o Parto; a peregrinação em busca do leito hospitalar e o excesso de intervenções desnecessárias, enquanto na rede suplementar a cesariana previamente agendada para as gestantes de classe média, atinge níveis elevados alcançando cerca de 88\% (LEAL, 2014).

Os principais resultados desta pesquisa indicam que mulheres e bebês estão submetidos a riscos desnecessários por hipermedicalização, independente da classe social e sofrem descaso as suas condições de vulnerabilidade por parte de profissionais de saúde.

As taxas de cesarianas no Brasil têm apresentado um aumento contínuo desde meados da década de 1990, em 2009 a proporção de cesarianas superou a de parto normais alcançando 52\%, taxa superior ao limite máximo de 15\% preconizado pela Organização Mundial da Saúde. Uma das razões apontadas pela categoria médica responsabiliza as mulheres pela escolha do Parto cirúrgico. Entretanto, uma revisão sistemática realizada recentemente indicou que apenas $20 \%$ das mulheres optam pela cesárea. O estudo ainda identificou que a decisão da via do parto é influenciada por fatores culturais, socioeconômicos, obstétricos, mas especialmente pela forma de pagamento efetuado pelo sistema público ou privado, indicando uma maior concentração de cesarianas no sistema privado, com taxa de $88 \%$, enquanto que no setor público essa taxa corresponde a $46 \%$ (DOMINGUES, et.al, 2014).

Os dados anteriormente comentados refletem o grande número de intervenções desnecessárias as quais as mulheres são submetidas na assistência ao parto. Leal (2014) aponta que os resultados perinatais brasileiros são insatisfatórios quando comparados a outros países que apresentam coeficientes de mortalidade neonatal e infantil inferiores aos nossos, bem como a razão de mortalidade materna e indicadores de intervenções mais satisfatórios.

Essa realidade é conhecida e confrontada pelas mulheres e profissionais comprometidos com a qualidade da assistência, desde o final da década de 1980, quando surgiu no Brasil o Movimento de Humanização da Assistência ao Parto (MHAP), reivindicando autonomia, direitos e respeito às mulheres em sua condição de diversidade (DINIZ, 2005).

O contexto histórico que favoreceu o surgimento do MHAP foi positivo, com experiências exitosas espalhadas pelo país, agregando múltiplos atores com modos 
alternativos de assistência ao parto, articulados a muitas instituições. A Rede pela Humanização do Parto e Nascimento (ReHuNa) agregou e mobilizou profissionais e representantes do segmento feminista para fortalecer outros modelos de assistência, para além do hegemônico, redefinindo a assistência ao parto com representação legítima das mulheres numa perspectiva de gênero, redimensionando de forma radical, o protagonismo da mulher no parto (DINIZ, 2005; RAMOS, 2013; TORNQUIST, 2004).

Essa perspectiva é aliada ao conhecimento da fisiologia do parto, fundamentandoa na Medicina Baseada em Evidências ${ }^{3}$ (MBE), como forma de buscar garantir uma assistência de qualidade. O MHAP reconhece a relevância do saber médico, mas faz oposição ao predomínio da tecnologia, utilizada sem critério ou em mau uso, uma vez que o parto não é um ato médico.

O modelo de assistência obstétrica que predomina na maioria dos países ocidentais, incluindo o Brasil, encara a saúde como problema, sendo as gestações, nesse modelo tecnocrático, potencialmente patológicas até que se prove o contrário, tornando-se assim um problema médico. Na contramão desse modelo, a enfermeira obstetra constitui uma profissional capacitada para oferecer um cuidado diferenciado, atuando na criação de vínculo, proporcionando bem-estar físico e emocional, transmitindo segurança, e conferindo autonomia à mulher (FREIRE et. al, 2017).

A obstetrícia se tornou uma especialidade da medicina e da enfermagem, porém as diferenças são importantes, uma vez que o médico obstetra privilegia a conduta ativa e o aparato tecnológico, agindo de maneira intervencionista, enquanto a enfermeira obstetra valoriza o encorajamento, a expectância, atuando como facilitadora do parto (OSAVA, 2009).

A EO é uma profissional regulamentada para assistir ao parto normal sem distócia com emissão do laudo de internação, através da Portaria GM n.163/1998, podendo atuar em maternidades, ligadas ou não a hospitais gerais, sendo que um percentual menor exerce sua profissão em casas de parto ou de maneira independente, em atendimento domiciliar (SAAD; RIESCO, 2018; CAAR; RIESCO; 2007).

Contudo, a cultura da medicalização construiu socialmente uma confiança no aparato tecnológico, levando as parturientes a procurarem os hospitais de grande porte, mesmo nos casos de gestação de risco habitual. Essa opção pelo parto institucional

${ }^{3} \mathrm{~A}$ MBE constitui um movimento internacional criado na segunda metade da década de 1980 e em poucos anos se estendeu ao mundo inteiro. Nasceu do reconhecimento de que boa parte das práticas médicas não estão respaldadas por estudos de qualidade sobre a segurança e a eficácia dos procedimentos utilizados, quer sejam os medicamentos, exames, cirurgias entre outros (ENKIN et al.2005). 
medicalizado sobrecarrega as maternidades de referência para gestações de alto risco, concentrando os procedimentos e decisões a todos os tipos de parto, a cargo da categoria médica (SAAD; RIESCO, 2018; MATTHEWS, 2006).

Dessa forma a atuação da EO depende das regras e normas da instituição onde ela está inserida, da divisão técnica do trabalho e da relação hierárquica com a categoria médica. Embora a Organização Mundial da Saúde (OMS) sustente que as EO têm autonomia para trabalhar e que são as profissionais mais indicadas para atender as gestações e partos de baixo risco, acompanhar situações de risco e reconhecer complicações, essa autonomia só é legitimada quando essa profissional atua em instituições onde não há presença do médico (casas de parto, e domicílio da mulher), expressando assim, que existe uma relação de classe e gênero influenciando diretamente nos processos de trabalho caracterizando a hegemonia médica como dispositivo da colonialidade do poder.

\section{METODOLOGIA}

O presente estudo consiste em uma revisão integrativa bibliográfica, de caráter qualitativo e exploratório, com objetivo de proporcionar a síntese do conhecimento e a incorporação dos resultados de estudos significativos na prática.

Para tanto, foi realizado uma busca aleatória incluindo os tópicos de enfermagem obstétrica, modelos assistenciais de saúde, e colonialidade do poder, no sentido de estabelecer uma aproximação com os temas, bem como a composição de uma fundamentação teórica que justificasse a relevância do estudo, e pudesse delimitar melhor os objetivos da pesquisa.

Trata-se, portanto, de um estudo motivado por um acontecimento prévio que gerou interesse na investigação, e consequentemente na identificação e descrição do objeto/fenômeno e dos fatores que se relacionam com ele, bem como pela busca de suas origens, fundamentando as hipóteses e estabelecendo relações entre as variáveis, característica do seu caráter exploratório (GIL, 1999; POLIT; BECK; HUNGLER, 2004).

Posteriormente, foi realizado um levantamento bibliográfico na Biblioteca Virtual de Saúde (BVS), sendo selecionadas as bases de dados eletrônicas: Base de Dados em Enfermagem (BDENF), Literatura Latino-Americana e do Caribe em Ciências da Saúde (LILACS), Scientific Eletronic Library Online (Scielo) e MEDLINE/PubMed em busca de textos que tratem sobre o tema de modo a responder os questionamentos propostos, e que tivessem indagação similar. 
Foi realizado uma busca dos documentos utilizando as palavras-chave: Enfermagem Obstétrica, Modelos de Assistência à Saúde, com associação a Colonialidade do poder e do saber. Os Descritores de Ciência em Saúde (DeCS) selecionados foram Enfermagem Obstétrica e Modelos de Assistência à Saúde, não sendo encontrado nenhum DecS que fizesse referência a colonialidade do poder e do saber.

Diante desse resultado cabe aqui um apontamento diante da relevância em relacionar a atuação das enfermeiras obstetras com a colonialidade do poder, visto que diante do observado em prática e evidenciado na literatura, apresenta-se a hipótese de que há uma relação entre o modelo assistencial obstétrico preponderante, com as conflitualidades entre os médicos obstetras e as enfermeiras obstetras, implicando no processo de autonomia da EO.

Os DeCS foram agrupados, para busca dos documentos nas bases de dados selecionadas. Os critérios de inclusão foram: textos disponíveis gratuitamente e integralmente nas bases de dados selecionadas, publicados entre os anos de 2010-2020, em língua portuguesa, inglesa ou espanhola. Foram excluídos do estudo, documentos que após leitura do resumo e/ou integral não se encaixaram nos objetivos do trabalho.

Os documentos selecionados foram organizados, e analisados através da análise temática de conteúdos proposta por Minayo (2007), onde a atenção é voltada para o conteúdo manifesto, suas significações e regularidades.

Operacionalmente, esse tipo de análise desdobra-se nas etapas de pré-análise, compreendida na leitura flutuante, e na constituição do corpus, que para Oliveira (2008) constitui o universo estudado; na exploração do material, onde foram elencadas as palavras e/ou expressões significativas; e no tratamento dos resultados obtidos/interpretação, onde foram classificados e agregados os conteúdos, a partir da escolha de categorias proposta por Bardin (1977).

\section{RESULTADOS E DISCUSSÃO}

Esta revisão integrativa iniciou-se com 79 documentos oriundos do cruzamento entre os DeCS “enfermagem obstétrica AND modelos de assistência de saúde”, nas bases de dados selecionadas. Após aplicação dos critérios de inclusão/exclusão, e leitura integral, sistemática, interpretativa e criteriosa dos textos selecionados, foram incluídos na revisão 04 documentos, que serão classificados nas categorias teóricas identificadas a partir dos eixos temáticos propostos no trabalho. 
Quadro2. Documentos inclusos na revisão bibliográfica ( $\mathrm{n}=04)$

\begin{tabular}{|c|c|c|c|c|c|}
\hline & TÍTULO & OBJETIVOS & $\begin{array}{l}\text { TIPO DO } \\
\text { ESTUDO }\end{array}$ & ANO & $\begin{array}{c}\text { LOCAL DE } \\
\text { PUBLICAÇÃO }\end{array}$ \\
\hline A1 & $\begin{array}{l}\text { Curso de aprimoramento para } \\
\text { enfermeiras obstétricas do Projeto } \\
\text { ApiceOn: relato de experiência }\end{array}$ & $\begin{array}{l}\text { Relatar as experiências } \\
\text { práticas vivenciadas no } \\
\text { Curso de } \\
\text { Aprimoramento para } \\
\text { Enfermeiros Obstetras } \\
\text { do projeto ApiceOn do } \\
\text { Ministério da Saúde. }\end{array}$ & $\begin{array}{l}\text { Estudo } \\
\text { descritivo na } \\
\text { modalidade } \\
\text { relato de } \\
\text { experiência. }\end{array}$ & 2020 & $\begin{array}{l}\text { Esc. Anna Nery Rev. } \\
\text { Enferm }\end{array}$ \\
\hline A2 & $\begin{array}{l}\text { Protagonismo de enfermeiras } \\
\text { obstétricas nas transformações das } \\
\text { situações reais de trabalho após um } \\
\text { curso de aprimoramento. }\end{array}$ & $\begin{array}{l}\text { Apreender } \\
\text { transformações as } \\
\text { situações reais de } \\
\text { trabalho, vivenciadas por } \\
\text { enfermeiros obstétricos } \\
\text { após um Curso de } \\
\text { Aprimoramento. }\end{array}$ & $\begin{array}{l}\text { Estudos de } \\
\text { casos } \\
\text { múltiplos, } \\
\text { com } \\
\text { abordagem } \\
\text { qualitativa, a } \\
\text { partir dos } \\
\text { pressupostos } \\
\text { teóricos e } \\
\text { metodológic } \\
\text { os da } \\
\text { avaliação de } \\
\text { quarta } \\
\text { geração. }\end{array}$ & 2018 & $\begin{array}{l}\text { Belo Horizonte, } \\
\text { (Dissertação de } \\
\text { Mestrado) }\end{array}$ \\
\hline A3 & $\begin{array}{l}\text { Assistência ao parto sob a ótica das } \\
\text { mulheres atendidas em um hospital } \\
\text { público }\end{array}$ & $\begin{array}{l}\text { Analisar a assistência ao } \\
\text { parto sob a ótica das } \\
\text { mulheres atendidas em } \\
\text { um hospital público de } \\
\text { ensino da cidade do } \\
\text { Recife-Pernambuco, } \\
\text { Brasil. }\end{array}$ & $\begin{array}{l}\text { Estudo } \\
\text { descritivo, } \\
\text { exploratório } \\
\text { com } \\
\text { abordagem } \\
\text { qualitativa. }\end{array}$ & 2014 & Rev. cuba. enferm \\
\hline A4 & $\begin{array}{l}\text { Como os trabalhadores de um } \\
\text { Centro Obstétrico justificam a } \\
\text { utilização de práticas prejudiciais ao } \\
\text { parto normal }\end{array}$ & $\begin{array}{l}\text { Entender as justificativas } \\
\text { dos trabalhadores de um } \\
\text { Centro Obstétrico do Sul } \\
\text { do Brasil para a } \\
\text { utilização de práticas do } \\
\text { parto normal } \\
\text { consideradas prejudiciais } \\
\text { pela Organização } \\
\text { Mundial da Saúde. }\end{array}$ & $\begin{array}{l}\text { A pesquisa é } \\
\text { do tipo } \\
\text { exploratória, } \\
\text { desenvolvida } \\
\text { em julho de } \\
2009 \text {, por } \\
\text { meio de } \\
\text { entrevista } \\
\text { com } 23 \\
\text { trabalhadore } \\
\text { s. }\end{array}$ & 2012 & $\begin{array}{lll}\text { Rev. Esc. Enferm. } \\
\text { USP }\end{array}$ \\
\hline
\end{tabular}

Fonte: elaborado pela autora

A partir da análise dos documentos, emergiram as seguintes temáticas: Reflexões acerca da Colonialidade do Poder, e do Saber na saúde; Panorama da assistência obstétrica: o modelo hegemônico e; O potencial da Enfermeira Obstetra.

\section{REFLEXÕES ACERCA DA COLONIALIDADE DO PODER E DO SABER NA SAÚDE}

A compreensão das conflitualidades existentes no âmbito da assistência ao parto, entre médicos obstetras e as enfermeiras obstetras tem origem histórica, com raízes profundas na colonialidade do saber e do poder, que foi socialmente instituída a partir da ciência moderna, alterando o modo de tratar e cuidar da saúde, medicalizando todos os 
ciclos da vida, para legitimação do biopoder, por meio do controle dos corpos pelo Estado, através da categoria médica.

No livro "Bruxas, Parteiras e Enfermeiras", as autoras Barbara Ehrenreich e Deirdre English fazem uma importante abordagem histórica de duas etapas diferentes acerca do processo da tomada do poder médico por parte dos homens, o que nos leva a refletir principalmente acerca dessa relação de poder entre gêneros. As mulheres foram, além de farmacêuticas, enfermeiras, as primeiras médicas da história ocidental. Compartilhando experiências, e aprendendo uma com as outras, passaram a ser conhecidas pela comunidade como "mulheres sábias", contudo para as autoridades eram bruxas e charlatonas condenadas a morrer na fogueira muito antes do surgimento da moderna tecnologia médica (ENRENREICH; ENGLISH, 1973).

A história convencional da medicina afirma que os profissionais masculinos dispõem de uma superioridade técnica sobre as mulheres, argumentando que estas são subordinadas em razão de uma ignorância que lhes foi imposta. A ciência masculina chegou para substituir a superstição feminina, e essa institucionalização não foi um acontecimento natural. A verdadeira origem dessa mudança no perfil dos responsáveis pela assistência à saúde da mulher está na longa história das lutas de classes e principalmente de gêneros impostas pelo poder durante o século XIX (ENRENREICH; ENGLISH, 1973).

Nesta categoria identificamos alguns estudos que abordam barreiras inerentes a autonomia da enfermeira obstetra, que atuam em instituições com a presença do médico. Os estudos apontam a existência de uma hierarquização entre esses profissionais, comprometendo severamente a atuação da enfermeira obstetra no campo da assistência.

Débora Cecília Chaves de Oliveira (2018), em sua dissertação (A2), afirma que existem problemas comuns já descritos na literatura que comprometem o poder de agir das enfermeiras obstetras, enfraquecendo seu gênero profissional, bem como sua categoria, estabelecidos pela dificuldade no processo de comunicação com a categoria médica, e a gestão institucional, implicando diretamente na qualidade da assistência. Estudos demonstram que a hierarquia, poder e conflitos nos serviços de saúde influenciam diretamente nas relações entre as categorias profissionais (OLIVEIRA, 2018).

De acordo com o artigo A3, de Leonildo Severino Silva, et. al (2015), existe uma diferença marcante entre os cuidados da enfermeira obstetra e a assistência oferecida pela categoria médica, uma vez que a enfermeira atua na perspectiva do cuidado com a mulher, através de práticas humanizadas e acolhedoras, enquanto a categoria médica atua a partir de práticas intervencionistas. O estudo enfatiza que essa divergência de práticas, produz 
conflitos, levando a equipe médica a duvidar dos cuidados oferecidos pela categoria das enfermeiras obstetras, julgando tais práticas como pouco científicas, e inapropriadas (SILVA et.al, 2015).

Essa atitude de relativizar os cuidados oferecidos pela enfermeira obstetra, legitima a colonialidade do poder uma vez que estudos apontaram que, embora a categoria médica reconheça que houve mudanças nas práticas assistenciais ao parto, desconsideram as recomendações dos órgãos internacionais, a exemplo da OMS e do MS, e continuam empregando práticas prejudiciais ao parto (SILVA et.al, 2015; OLIVEIRA, 2018).

Vanessa Franco de Carvalho, et. al. (2012), autores do artigo A4, ao analisar os depoimentos dos sujeitos entrevistados em seu estudo sobre as justificativas dos trabalhadores de um Centro Obstétrico do Sul do Brasil para a utilização de práticas consideradas prejudiciais pela OMS, evidenciou que o emprego de algumas dessas práticas está diretamente relacionado ao plantonista “(...) os profissionais médicos preferem que se faça. Dižem que não é recomendado, mas aqui eles ainda preferem que se faça (E2)”. Os mesmos autores evidenciaram que as práticas assistenciais estão na dependência da crença e saber dos plantonistas. Cabe ressaltar que o local desse estudo foi uma instituição de ensino, que deveria ter a responsabilidade de formar futuros trabalhadores de saúde, tomando as políticas e programas do MS como referência das ações de saúde do país (CARVALHO et. al, 2012).

Baseado nesses estudos é possível inferir que a formação da categoria médica não está incluindo em seus conteúdos de atualização das práticas assistenciais, propostas pela medicina baseada em evidências. Esses estudos também identificaram associação direta entre a colonialidade do poder, e a utilização das práticas intervencionistas que controlam os corpos das mulheres.

O artigo A3 identificou que as condutas intervencionistas comprometem a saúde das mulheres enquanto direito reprodutivo, indicando ainda que existe um sentimento de indignação das parturientes diante do desrespeito à sua autonomia no processo decisório, resultante da imposição de condutas, e da verticalização de ações (SILVA et. al, 2015).

Historicamente, a assistência ao Parto constitui um campo de disputa entre as categorias médica e de enfermagem, especialmente na área da obstetrícia que tem como viés os aspectos de classe e gênero no que diz respeito à autonomia da assistência ao Parto normal, como descreve Ramos (2013):

Entre um grupo que detém a hegemonia e a legitimidade quase incontestável no campo, os médicos, e um grupo que busca uma identidade autônoma e legítima (o das enfermeiras obstétricas), mas ainda de forma bastante subordinada [...] O ônus da violência recai, ainda, apenas sobre as mulheres. Portanto, o conflito em 
meio a esse cenário pode ser entendido como uma forma de lidar com a responsabilização, na disputa das legitimidades e hierarquizações do campo obstétrico (RAMOS, 2013 p. 299-300).

De acordo com os estudos eleitos para essa categoria, a Colonialidade do poder/saber produz e reproduz conflitos no campo da assistência ao parto, legitimando o modelo hegemônico autoritativo que não encontra base nas evidências científicas, e compromete severamente o panorama da assistência obstétrica.

\section{Panorama da assistência obstétrica: o modelo hegemônico}

A atenção obstétrica mundial está passando por um período intenso de reavaliação de dados e evidências, em busca da redução da mortalidade materno-infantil e da qualificação da assistência. Constatou-se que o modelo de assistência obstétrica que predomina na maioria dos países ocidentais, incluindo o Brasil, encara a saúde como problema, sendo as gestações, nesse modelo tecnocrático e hospitalocêntrico, potencialmente patológicas até que se prove o contrário, tornando-se assim um problema médico. Embora precisemos reconhecer a importâncias dos avanços técnico-científicos na redução dos riscos materno-fetais, estudos mostram quão prejudiciais se tornam quando utilizados indiscriminadamente (FREIRE et. al, 2017).

Atualmente há uma discussão ampla no país sobre a insatisfação das mulheres com o modelo assistencial excessivamente intervencionista, que lhe tira a autonomia gerando descontentamento (SILVA et. al, 2015).

Estudos inclusos nessa revisão indicam o modelo tecnocrático como o hegemônico nas instituições públicas e privadas no país. O Inquérito Nascer no Brasil, estudo referência do cenário obstétrico brasileiro, aponta que as mulheres brasileiras de todos os grupos socioeconômicos de risco obstétrico habitual estão sendo expostas a iatrogenias, decorrentes das intervenções desnecessárias pelos efeitos adversos do uso excessivo da tecnologia. Para as mulheres do grupo socioeconomicamente vulnerável, existem dados da violência obstétrica provocada, por tratamento desrespeitoso e procedimentos dolorosos, a exemplo da aceleração do trabalho de parto com administração de ocitócitos e baixo uso de analgesia, enquanto que para as mulheres do grupo economicamente mais elevado, essas são vítimas da epidemia de cesarianas eletivas (LEAL et. al, 2014).

Esse inquérito aponta o modelo tecnocrático como responsável por altas taxas de mortalidade materno-infantil, pelo desrespeito aos direitos sexuais e reprodutivos das 
mulheres, que reduz o parto a um fenômeno patológico, médico e fragmentado. Embora consista de uma vivência feminina plena de afeto e sexualidade, o uso de intervenções excessivas durante o processo parturitivo acarreta efeitos devastadores tanto físicos quanto psicológicos, para o binômio mãe-bebê (LEAL et. al, 2014).

O estudo A2 identificou que o Brasil enfrenta uma epidemia de cesariana, alcançando a taxa de 55,5\% em 2015. O país enfrenta um "paradoxo" devido à intensa medicalização do processo de parto e nascimento, altas taxas de morbimortalidade materna e perinatal por meio da utilização de práticas comprovadamente ultrapassadas e iatrogênicas, mesmo quando apresenta 98\% dos partos em ambientes hospitalares (OLIVEIRA, 2018; BRASIL, 2014; BRASIL 2015; DINIZ, 2009; DINIZ; D’OLIVEIRA e LANSKY, 2012).

O estudo A4 reconhece que a falta de um protocolo de atendimento baseado em evidências científicas favorece a perpetuação do modelo tecnocrático, tendo a instituição a responsabilidade em orientar seus trabalhadores para um atendimento adequado e de qualidade. Ademais, o artigo aponta que apesar da unidade que representou o lócus do estudo não possuir um protocolo de atendimento à parturiente, foi evidente a existência de uma rotina oculta no local, pois houve semelhança nas respostas dos trabalhadores quando questionados sobre as práticas prejudiciais ao parto (CARVALHO et.al, 2012).

Os autores desse estudo afirmam que a rotina existente na unidade se configura como empecilho para mudanças, visto que as condutas são passadas intergeracionalmente e perpetuadas como verdadeiras ao longo do tempo, sendo necessário a iniciativa de um trabalhador ou gestor para que se estabeleça uma discussão que leve a reflexão acerca da necessidade da mudança do modelo assistencial (CARVALHO et.al, 2012).

Nessa perspectiva, as atuais políticas de saúde apontam para a necessidade de promover a autonomia da mulher nos serviços de saúde reprodutiva, uma vez que a falta de informação leva as gestantes a acreditarem que apenas os recursos tecnológicos são suficientes para oferecer uma assistência de qualidade. Contudo, nesse modelo, há predomínio de ações prescritivas que não valorizam as vivências e saberes tradicionais no campo do cuidado. As participantes do estudo A6 associam o conceito de "ser bem atendida”, às intervenções praticadas na fase expulsiva do parto (SILVA et.al, 2015).

Em sua dissertação (A1) Oliveira (2018) aponta dois desfechos possíveis atualmente para a parturiente que busca os serviços de saúde no país. O primeiro seria um parto vaginal com altas possibilidades de intervenções desnecessárias e/ou prejudiciais ao binômio mãe-bebê, marcado por violência obstétrica, e o segundo uma cesariana sem 
indicação clínica, na maioria das vezes. A autora também faz referência a uma revisão integrativa que teria apontado como principais temáticas emergentes nas publicações brasileiras, a cesárea como "problema de saúde pública", o profissional "médico" na prática da cesárea, e a "preferência da mulher", a "livre escolha" versus "empoderamento feminino", além da "mercantilização" do cuidado ao parto, e do cenário sociocultural, de segurança e planejamento do país (OLIVEIRA, 2018; RISCADO; JANNOTTI; BARBOSA, 2016)

O estudo A3 recomenda que a ações de humanização e acolhimento sejam implementadas desde a admissão, sendo a trajetória da admissão ao parto um percurso determinante para a não exposição da mulher a riscos evitáveis. O mesmo estudo reconhece que embora existam instituições onde a humanização e o acolhimento norteiam as práticas de saúde, o protagonismo do parto tem sido do profissional de saúde, destacando a necessidade de valorizar a promoção da autonomia plena da parturiente (SILVA et.al, 2015).

Os profissionais da saúde obstétrica devem compreender que a mulher em trabalho de parto precisa receber um cuidado humanizado e seguro, garantindolhe os benefícios dos avanços científicos (SILVA et.al, 2015).

Diante dessa discussão, é necessário trazer à baila as divergentes formas de assistir ao parto de acordo com o profissional responsável. Os estudos relatam que a quantidade maior de intervenções está associada ao atendimento pela categoria médica.

Ao contrário das intervenções tecnicistas, a enfermeira obstetra utiliza de recursos não invasivos para conduzir o trabalho de parto, valorizando o processo fisiológico natural do corpo da parturiente, e atuando como incentivadora desse auto-conhecimento por parte da mulher. A utilização de métodos não farmacológicos para alívio da dor, como massagens, banhos de chuveiro ou banheira, a utilização de instrumentos como a bola suíça, cavalinho, dentre outros que auxiliam a parturiente a encontrar a posição mais confortável para a evolução do trabalho de parto, bem como orientações para uma respiração tranquila, posicionamento verticalizado, propostos pelas EO causam estranhamento entre os profissionais médicos, que consideram esses recursos como pouco científicos e inapropriados, como evidenciado no estudo A3 (SILVA et.al, 2015).

Em sua dissertação Oliveira (2018) considera que desmedicalizar o nascimento não consiste em excluir a figura do médico do parto, e sim eliminar o raciocínio clínicomédico como única forma de parir, apresentando assim, outras opções de cuidado baseado no cuidado e no protagonismo e autonomia da mulher (OLIVEIRA, 2018; PROGIANTI e DA COSTA VARGENS, 2004). 
Silva et. al. (2015) no A3 ressaltam que a substituição do profissional médico pela EO na assistência ao parto normal não necessariamente humaniza a assistência. É preciso que o profissional entenda a necessidade de um cuidado integral, que empodere e respeite as necessidades da mulher. Os autores reconhecem que a enfermagem atua na perspectiva do cuidado, utilizando de procedimentos técnicos científicos, e propõe a mudança do cenário intervencionista para práticas humanizadas e acolhedoras (SILVA et.al, 2015).

\section{O Potencial da Enfermeira Obstetra}

Com o avanço tecnológico da assistência ao parto, a obstetrícia se tornou uma especialidade da medicina e da enfermagem, porém há diferenças importantes no modo de cuidado de cada profissional. Enquanto o médico obstetra privilegia a conduta ativa e o aparato tecnológico, a enfermeira obstetra valoriza o encorajamento, a expectância, atuando como facilitadora do parto (OSAVA, 2009).

$\mathrm{Na}$ contramão do modelo tecnocrático, a enfermeira obstetra se mostra uma profissional que atua com um cuidado e postura diferenciados, atuando na criação de vínculo, proporcionando bem-estar físico e emocional, transmitindo segurança, e conferindo autonomia a mulher, sendo valorizada pelas gestantes (FREIRE et.al, 2017).

No A1, Sanfelice et. al. (2020) fazem referência a um relatório sobre o "Estado da Enfermagem Obstétrica no Mundo", elaborado pela Organização Pan-americana de Saúde, em conjunto com a OMS e a Confederação Internacional de Parteiras (ICM), que reconhece a EO como profissional capaz de exercer 90\% dos cuidados essenciais para mulheres e recém-nascidos, podendo contribuir para a redução em dois terços da mortalidade materna.

As autoras (A1) também evidenciam que além da capacidade técnica, as EO apresentam uma postura proativa, comprometida e de forte envolvimento e responsabilidade com a comunidade, fortalecendo a segurança e o vínculo das usuárias com a instituição (SANFELICE et.al, 2020).

Para a política econômica neoliberal, a atuação da EO representa ação fundamental, porque investe em um processo de trabalho que é baseado em tecnologias leves, uma forma de redução dos custos (PROGIANTI et.al, 2018).

No A1, Sanfelice et. al. (2020) relata as experiências práticas vivenciadas no Curso de Aprimoramento para Enfermeiras Obstetras do projeto ApiceON, do MS, onde é possível inferir acerca do potencial da EO numa instituição modelo de boa qualidade de assistência obstétrica do país. As participantes do estudo consideram a forma de trabalho 
das EO exitosa, pois há valorização da autonomia e potencial das EO, que prestam uma assistência acolhedora, resolutiva e humana, como preconizado pela Política Nacional de Humanização.

As EO da instituição do estudo A1 têm autonomia para utilizar de boas práticas de assistência ao parto e nascimento, conforme recomendado pelas atuais diretrizes nacionais e internacionais, tais como estimular a deambulação no trabalho de parto, a participação ativa do acompanhante durante todos os estágios do trabalho de parto, utilizar métodos não farmacológicos para alívio da dor, assegurar a liberdade de posição, estimular posicionamento verticalizado para o parto, garantir o direito à alimentação e hidratação oral por todo período do trabalho de parto e pós-parto imediato, além de se vincular horizontalmente com a mulher, a partir do diálogo e da participação efetiva da mulher nas decisões a serem tomadas. Essas práticas se alinham ao recomendado pelas recentes evidências científicas, e traduzem um atendimento seguro e com bons desfechos maternos e neonatais (SANFELICE et.al, 2020).

A qualificação profissional apresentada deveria ser um pilar sólido para a inserção dessas profissionais na assistência direta ao parto, visto que a literatura demonstra que pode contribuir com a melhoria dos indicadores maternos e neonatais. Porém, há dificuldade de inserção e atuação dessas profissionais no território nacional, e está relacionada a diversos fatores, dentre eles déficit de conhecimento teórico, falta de experiência prática, e principalmente a disputa de espaço com a equipe médica, como discutido ao longo desse trabalho (SANFELICE et.al, 2020).

As autoras do A1 apontam que quando inseridas nas instituições tradicionais, as EO acabam sendo desfavorecidas em sua assistência, e acabam sendo obrigadas a reproduzirem um modelo tecnocrático, com práticas desaconselhadas e prejudiciais (SANFELICE et.al, 2020).

Nesse sentido, cabe refletir sobre a autonomia da enfermeira obstetra no cenário obstétrico nacional, a partir do estudo de Saad e Riesco (2018):

A autonomia profissional pressupõe determinado grau de exercício de poder,
conhecimento teórico e prático, reconhecimento do ambiente de atuação,
competências para fazer escolhas, capacidades para agir e decidir e
responsabilidade na tomada de decisões (SAAD; RIESCO, 2018, p.12).

De acordo com a Confederação Internacional de Parteiras (ICM), a competência da EO é atribuída ao conjunto de conhecimentos e habilidades práticas que essas profissionais devem reunir, para exercer a profissão de maneira segura e efetiva. Os resultados exitosos da atuação da EO, que dispõe de autonomia, indicam o aumento da autoestima e 
autoconfiança das profissionais, bem como uma assistência de melhor qualidade, conforme o reconhecimento de seus direitos e deveres perante as mulheres e os outros profissionais envolvidos (SAAD; RIESCO, 2018).

Quando essas condições são alcançadas, a EO consegue estabelecer-se profissionalmente, oferecendo à mulher um cuidado qualificado, numa perspectiva integral, repercutindo positivamente no nível de satisfação das mulheres, reduzindo o número de intervenções, o tempo de internação, e consequentemente reduzindo os custos do atendimento (SAAD; RIESCO, 2018).

\section{CONSIDERAÇÕES FINAIS}

A revisão identificou que existem conflitualidades no campo de atuação da enfermeira obstetra, com raízes históricas, associadas a colonialidade do poder e do saber, enquanto dispositivo que segmentou os conhecimentos em tradicionais e científicos (advindo da ciência moderna), hierarquizando as relações entre médicos e parteiras tradicionais, hoje representadas pelas EO. Esse processo de hierarquização de saberes desencadeou problemas a partir da institucionalização do parto, com a entrada da categoria médica no campo da assistência.

A transferência do parto domiciliar para o hospital representou mudanças profundas no significado desse processo, que era compreendido como evento fisiológico, na ótica das parteiras tradicionais, passando a representar um evento de risco na concepção médica. Até meados do séc. XIX as parteiras tradicionais cuidavam das mulheres no domićlio, constituindo uma rede de solidariedade feminina, baseada nos saberes tradicionais, no afeto, na família, e na fé.

Na contramão dessa concepção integrativa, a cultura do Biopoder, desenvolvida a partir da ciência moderna, estabeleceu novos sentidos para o parto numa lógica de patologização do processo parturitivo, no sentido de controlar os corpos das mulheres pela medicina através de dispositivos disciplinares, evidenciados no modelo tecnocrático de assistência, que foi construído a partir da visão mecanicista, separando o corpo da mente, impondo uma organização hierárquica e um atendimento padronizado, supervalorizando a ciência e tecnologia, através do excesso de intervenções, direcionado para o lucro.

Nesse contexto, foi socialmente construída a categoria da Enfermagem Obstétrica, ancorada nas relações de poder, gênero e classe, onde a categoria médica permanece atuando na lógica da colonialidade, e a enfermagem obstétrica refém desse modelo autoritativo, vez que a formação dessa profissional não inclui em seus conteúdos 
programáticos temas que favoreçam a reflexão da história da sua profissão, a exemplo da colonialidade do poder e saber, da institucionalização do parto e do biopoder.

Assim, para promover mudanças efetivas no campo da atuação da EO no que diz respeito a sua autonomia, é relevante incluir temas que subsidiem reflexões políticas a respeito da história dessa profissão. Há, portanto, a necessidade de se humanizar a relação parturiente-profissional respeitando a integralidade e a autonomia da mulher, valorizando a importância das tecnologias leves, baseadas nos processos relacionais em contraponto as tecnologias duras, características do modelo tecnocrático predominante no sistema de saúde brasileiro, inseridas nesse cenário a partir dos pressupostos da colonialidade do poder.

Recebido para publicação em 20 de setembro de 2021.

Aceito em 08 de novembro de 2021.

\section{REFERÊNCIAS}

BRASIL. Humanização do parto e do nascimento. Ministério da Saúde. Universidade Estadual do Ceará- Brasília: Ministério da Saúde, (Cadernos HumanizaSUS), v.4,2014. Disponível em $<$ http://www.redehumanizasus.net/sites/default/files/caderno humanizasus v4 humani zacao parto.pdf>. Acesso em: 08/09/2019.

BRASIL. Ministério da Saúde. Portaria GM/MS no 1459, de 24 de junho de 2011. Institui no âmbito do SUS a Rede Cegonha. Diário Oficial da União. Brasília: Ministério da Saúde, 2011.

CARneiro, R.G. Cenas de Parto e Políticas do Corpo. FIOCRUZ. 2015.

CAUS, E.C.M; SANTOS, E.K.A; NASSIF, A.A; MONTICELLI, M. O processo de parir assistido pela enfermeira obstétrica no contexto hospitalar: Significados para as parturientes. Escola Anna Nery Revista de Enfermagem,2012. Disponível em < http://www.scielo.br/pdf/ean/v16n1/v16n1a05.pdf>. Acesso em: 16/06/2019.

DAVIS-FLOYD, R. CultureandBirth: The TechnocraticImperative. InternationalJournalofChildbirthEducation, 9(2):6-7, 1994.

DAVIS-FLOYD, R. Birth as an American RiteofPassage, 2003.

DAVIS-FLOYD, Robbie e SARGENT, Carolyn F. Childbirthandauthoritativeknowledge: cross-cultural perspectives. United States: UniversityofCalifornia Press, 1997.

EHRENREICH, B.; ENGLISH, D. Witches, midwives, and nurses. New York, Feminist Press, 1973. 
FREIRE, H.S.S; CAMPOS, F.C; CASTRO, R.C.M.B; COSTA, C.C; MESQUITA, V.J; VIANA, R.A.A. Parto normal assistido por enfermeira: experiência e satisfação de puérperas. Revista de Enfermagem UFPE Online, 2017. Disponível em < https://periodicos.ufpe.br/revistas/revistaenfermagem/article/view/23398/19057> Acesso em 28/08/2019.

GARCIA, S.L; LIPPI, U.G; GARCIA, S.A.L. O parto assistido por enfermeira obstetra: Perspectivas e controvérsias. Revista Brasileira em Promoção da Saúde. 2010. Disponível em <https://periodicos.unifor.br/RBPS/article/view/2041/2335>. Acesso em: 21/07/2019.

MELO, C.P.L. A (des)colonialidade do parto: reflexões sobre o movimento de humanização da parturição e do nascimento. 2013. Apresentação de Trabalho/ Congresso. Disponível em: . Acesso em: 10 jul. De 2017.

MENEZES, P.F.A; PORTELLA, S.D.C; BISPO, T.C.F.A Situação do Parto Domiciliar no Brasil. Revista Enfermagem Contemporânea. 2012.

MOTT, M. L. Fiscalização e formação das parteiras em São Paulo (1880-1920). Revista de Enfermagem da USP 13(1), 2001, pp. 46-43.

OSAVA, R.H. Autonomia na atenção ao parto e nascimento: Espaço físico e político do enfermeiro obstetra e obstetriz. VI Congresso Brasileiro de Enfermagem Obstétrica e Neonatal. Teresina-PI. 2009. Disponível em <https://docplayer.com.br/15268018Autonomia-na-atencao-ao-parto-e-nascimento-espaco-fisico-e-politico-do-enfermeiroobstetra-e-obstetriz.html>. Acesso em 27/07/2019.

PROGIANTI, J.M; MOREIRA, N.J.M.P; PRATA, J.A; VIEIRA, M.L.C; ALMEIDA, T.A; VARGENS, O.M.C. Precarização do trabalho da enfermeira obstétrica. Rev. Enfermagem UERJ,2018. Disponível em $\quad$ https://www.epublicacoes.uerj.br/index.php/enfermagemuerj/article/view/33846> $>$ Acesso em 02/09/2019.

QUIJANO,A.Colonialidade do Poder e Classificação Social.In:Epistemologias do Sul / org. Boaventura deSousa Santos, Maria Paula Meneses. - (CES).2005 ISBN 978-972-403738-7

RAMOS, T. O. Casas de parto autônomas no contexto brasileiro: conflitualidades e sentidos em torno da humanização de partos e nascimentos. 2013. 351 f., il. Tese (Doutorado em Sociologia)—Universidade de Brasília, Brasília, 2013.

SANFELICE, C.F.O; ABBUD, F.S.F; PERGNOLATTO, O.S; SILVA, M.G; SHIMO, A.K.K. Do parto institucionalizado ao parto domiciliar. Rev Rene. 2014. Disponível em < http://periodicos.ufc.br/rene/article/view/3170/2433>. Acesso em 10/06/2019.

TORNQUIST, Carmem Susana. Parto e Poder: análise do movimento pela humanização do parto no Brasil. Florianópolis: Universidade Federal de Santa Catarina, 2004. Tese (Doutorado). 


\title{
OBSTETRIC NURSING: ASSISTANCE IN BIRTH IN BRAZIL REFLECTIONS OF THE COLONIALITY OF POWER AND KNOWLEDGE
}

\begin{abstract}
This is an integrative bibliographical review, exploratory and qualitative, which aimed to analyze the influence of the coloniality of power and knowledge in the care practices of obstetric nurses in institutional childbirth, presenting the conflicts between professionals working in the field. of childbirth care, and characterizing the hegemonic care model in Brazil. The bibliographic survey was carried out in the Virtual Health Library. The documents were analyzed using the thematic content analysis method. Three themes emerged: Reflections on the Coloniality of Power and Knowledge in Health; Overview of obstetric care: the hegemonic model; The potential of the Obstetric Nurse. It was found that there are conflicts in the field of work of the obstetric nurse, arising from historical processes associated with the Coloniality of Power and Knowledge, triggered from the institutionalization of childbirth.
\end{abstract}

Keywords: Obstetric Nursing; Health Care Models; Coloniality of power/knowledge.

\section{SOINS INFIRMIERS OBSTÉTRIQUES: ASSISTANCE À LA NAISSANCE AU BRÉSIL RÉFLEXIONS SUR LA COLONIALITE DU POUVOIR ET DU SAVOIR}

Resumen: Se trata de uma revisión bibliográfica integradora, exploratoria y cualitativa, que tuvo como objetivo analizar la influencia de la colonialidad del poder y el conocimiento em las prácticas asistenciales de las enfermeras obstétricas em el parto institucional, presentando los conflictos entre los profesionales que laboran em el campo del cuidado del parto, y caracterizando el modelo asistencial hegemónico em Brasil. La encuesta bibliográfica se realizó em la Biblioteca Virtual em Salud y los documentos se analizaron mediante el método de análisis de contenido temático. Surgieron tres temas: Reflexiones sobre la colonialidad del poder y el conocimiento em salud; Panorama de la atención obstétrica: el modelo hegemónico; El potencial de la enfermera obstétrica. Se encontró que existen conflictos em el ámbito laboral de la enfermera obstétrica, derivados de procesos históricos asociados a la Colonialidad del Poder y el Conocimiento, desencadenados a partir de la institucionalización del parto.

Mots-clés: Contraseñas: Enfermería obstétrica; Modelos de atención de la salud; Colonialidad del poder / conocimiento

\section{Tainá Santana de Deus Oliveira}

Enfermeira. Graduada pela Universidade do Estado da Bahia- UNEB. Pós-graduanda em Aleitamento Materno.

\section{Mary Lúcia Souto Galvão}

Possui graduação em Enfermagem e Obstetrícia pela Universidade Católica do Salvador (1980) e Mestrado em Enfermagem pela Universidade Federal de São Paulo (1995). Atualmente é professora titular da Universidade do Estado da Bahia na área de Saúde da Mulher do curso de Enfermagem. Coordenadora do Projeto de Extensão Acolhendo à Gestação, Coordenadora do Projeto de Extensão Valorização de Saberes de Parteiras Quilombolas em convênio com o Ministério da Saúde/UNEB/OPAS. Coordenadora do Projeto de Extensão Roda da Saúde da Secretaria de Gestão Participativa do Ministério da Saúde/UNEB tendo como objeto capacitação de lideranças e conselhos distritais do Distrito Sanitário Cabula Beiru. 


\section{Ticiana Oswald Ramos}

Professora Adjunta da Universidade Federal do Recôncavo da Bahia, Centro de Ciências da Saúde, Campus Santo Antônio de Jesus. Socióloga, mestre e doutora em sociologia pela Universidade de Brasília. Sanitarista, com especialização em Saúde Pública. Atuou como professora de ciências sociais e metodologia da pesquisa científica, consultora, pesquisadora e técnica de políticas de saúde. Ás áreas de maior experiência profissional e pesquisa incluem temáticas de políticas públicas de saúde, saúde das mulheres, assistência ao parto, humanização do parto, Casas de Parto (Centros de Parto Normal) e parteiras tradicionais. Possui interesse também em temáticas da cultura, como manifestações culturais de tradições afro-brasileiras, povos e comunidades tradicionais, decolonialidade e interdisciplinaridade, bem como as transversalidades de gênero, raça/etnia e geração. Atua na implantação do "Encontro de Saberes" no CCS/UFRB. 